\title{
Primary syphilis as oral lesion in HIV/AIDS-positive patient: case report of unusual manifestation
}

Isabella Eloy de Souza Barbaresco Damiani, Maria Angela Naval Machado, Melissa Rodrigues de Araújo, Antonio Adilson Soares de Lima

Universidade Federal do Paraná, Curitiba, Brazil

\begin{abstract}
Introduction: Syphilis is a sexually transmitted infection caused by Treponema pallidum bacterium. Oral manifestations of syphilis are always a challenging diagnosis because broad clinical aspect is easily missed due to other oral manifestations of local, infectious, or systemic origins. In addition, in HIV-positive patients, primary syphilis can usually have a symptomless course.

Case description: A 44-year-old HIV-positive male patient, living with the infection for 17 years, working as a sex worker, presenting primary syphilis with syphilitic ulceration of the tongue. The lesion was unique, indurated, with irregular margins and whitish/red base. The patient reported no pain or discomfort in the lesion. This last information along with a detailed oral clinical examination was important to help exclude initial diagnostic hypothesis of traumatic ulcer and other oral manifestations. Diagnosis of syphilis was only made after clinical history of patient being associated with data of chemiluminescent microparticle immunoassay and venereal disease research laboratory.

Conclusions: Health professionals should be aware of possible oral manifestations of primary syphilis, especially at risk groups. Moreover, the association of clinical history with laboratory tests is necessary for final diagnosis.
\end{abstract}

HIV AIDS Rev 2022; 21, 1: 83-87

DOI: https://doi.org/10.5114/hivar.2022.112682

Key words: HIV, Treponema pallidum, HIV infection, dental care, syphilis.

\section{Introduction}

Syphilis is a sexually transmitted infection caused by anaerobic bacterium, Treponema pallidum [1]. This disease only occurs in humans, and has complex clinical manifestations [1]. In addition to transmission through sexual contact, contamination can occur through blood transfusion and placenta [2]. This disease presents four main stages, including primary, secondary, latent, and tertiary syphilis [3]. Primary syphilis is characterized by one or multiple painless

Address for correspondence: Isabella Eloy de Souza Barbaresco Damiani, Universidade Federal do Paraná, Curitiba, Brazil, e-mail: isa_damiani@hotmail.com chancre at the site of inoculation (syphilitic ulceration) [1]. They usually regress without any treatment [1]. Secondary syphilis manifests as generalized mucocutaneous lesions on the lymph nodes, skin, mucosa, and characteristically, on the palms of hands and the soles of feet [4]. If the disease is not treated, the latent phase begins. It has no clinical manifestations, and is divided into early (less than one year of infection) and late (more than one year of infection) latent phase [4]. Tertiary syphilis has long-term complications, and

Article history:

Received: 29.11.2020

Revised: 02.05.2021

Accepted: 29.09.2021

Published: 03.01.2021
International Journa of HIV-Related Problems

HIV \& AIDS Re vie w 
its' signs are 'gums' that can affect the skin, liver, central nervous system, spleen, and other organs [1].

Oral manifestations of syphilis are uncommon and difficult to diagnose because of their broad clinical appearance [5]. Syphilis ulcerations may appear as a result of changing sexual habits, more specifically, an increase in practice of oral sex [6]. They manifest clinically as a single ulcer on the lip (usually on the upper lip in men and lower in women), gingiva, soft palate, or tongue $[5,7]$. Regional cervical lymphadenopathy may be present in $80 \%$ of cases [1]. In individuals with primary syphilis, syphilitic ulcerations are seen in 4 to $12 \%$ of patients [1].

In patients infected with HIV, clinical course of the disease is often atypical, therefore diagnosis becomes even more difficult [1]. However, in these individuals, primary syphilis appears to be less frequent than secondary syphilis [8]. The objective of this study was to report a case of HIV-positive patient with clinical manifestation of primary syphilis in the oral cavity.

\section{Case description}

A 44-year-old male was admitted to the Hospital Oswaldo Cruz (Curitiba-PR, Brazil) due to convulsive crisis and loss of memory. During anamneses, he reported being HIV-positive and not using treatment regularly. Physical examination revealed fever, malaise, cough, and chest pain. A chest X-ray and sputum smear microscopy were performed, and results confirmed pulmonary tuberculosis. The patient was introduced to treatment protocol for this disease, with rifampicin $150 \mathrm{mg}$, isoniazid $75 \mathrm{mg}$, pyrazinamide $400 \mathrm{mg}$, and ethambutol $275 \mathrm{mg}$. Oral examination of the patient revealed bad oral health with carious lesions, periodontal disease, residual roots, teeth loss, coated tongue, and oral ulcer on the left side of the tongue. The lesion was approximately $9 \mathrm{~mm}$ in diameter, with raised and whitish edges, and undetermined evolution time. The bottom of the lesion was granulomatous (Figure 1). The patient reported no discomfort at the site of the injury. Initially, due to poor oral health, the patient

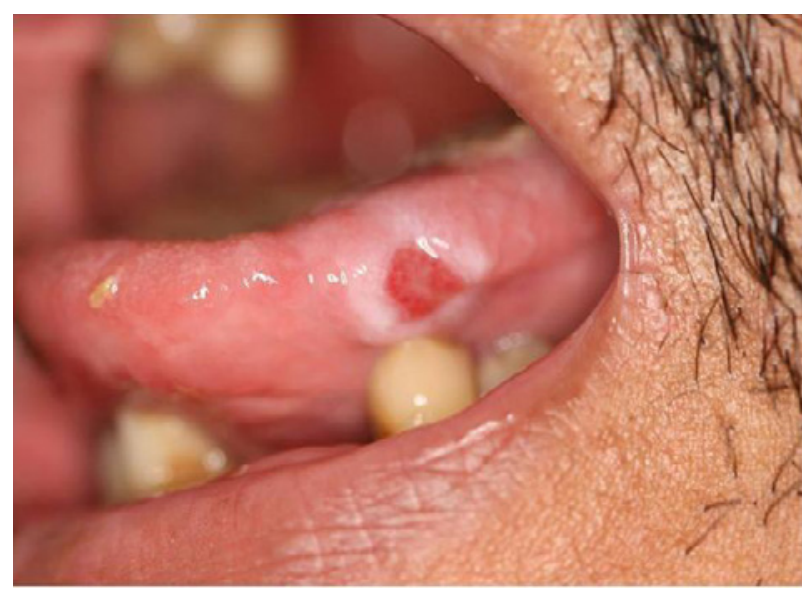

Figure 1. Ulcer of the tongue associated with syphilis was instructed to brush the tongue to remove the coating. In addition, he was referred for dental treatment in the school of dentistry of the Universidade Federal do Paraná (Curitiba, Brazil).

The hospital protocol requires an assessment of patient's general health through medical examination and various laboratory tests. Table 1 presents laboratory tests and their respective results. The patient had neutrocytosis and altered values for the following exams: erythrocyte sedimentation rate, liver enzymes, C-reactive protein, and HIV viral load. Moreover, he had thrombocytopenia, and low levels of serum calcium and CD4+ lymphocyte count. The patient was reintroduced to antiretroviral therapy (tenofovir $300 \mathrm{mg}+$ lamivudine $150 \mathrm{mg}+$ efavirenz $600 \mathrm{mg}$ ).

The ulcer on the tongue had the characteristics of a chronic lesion. The central region had a granulomatous aspect and with slightly elevated margins. Thus, the first hypothesis of diagnosis was an ulcer caused by local trauma. However, no type of irritating agent has been identified, such as fractured dental crown, poorly polished/misfit, or irregular surface restorations. Due to the clinical characteristics of the oral lesion and the fact that the patient has HIV, two diagnostic hypotheses were raised: oral lesion associated with tuberculosis or syphilis. As oral lesions caused by tuberculosis are rare, tests to investigate syphilis have been carried out. In addition, incisional biopsy was performed. The result of chemiluminescent microparticle immunoassay showed reagent, with value of 37.59. Anatomo-pathological examination revealed an ulcer with a granulomatous inflammatory infiltration. Proliferation of endothelial cells and perivascular inflammatory infiltrate with lymphocytes and plasma cells were present within the underlying connective tissue (Figure 2). All of these tissue changes are seen in primary syphilis lesions.

The patient was questioned about his sexual practices; he confirmed working as a prostitute and not using condoms regularly. In this way, the diagnosis of primary syphilis was established. The treatment of syphilis was carried out with benzathine penicillin G 2.4 million units injected once intramuscularly. The lesion disappeared completely after 7 days. Periodic consultations were scheduled every 3 months during a year to observe evolution of the treatment. No similar secondary syphilis lesions were observed, and the levels of entitlement of venereal disease research laboratory (VDRL) decreased.

\section{Discussion}

The primary site of syphilis infection occurs as local Treponema pallidum inoculation, usually in the genital region. However, it can also occur at extra-genitally sites [7]. The oral mucosa region is the most common site of manifestation of primary syphilis in extragenital sites [9]. This initial phase of the disease is characterized by single or multiple painless chancre, with demarcated margins, with no pus, and clean base known as 'chancre'. In the oral cavity, chancre can appear on the lips, tongue, palate, and tonsils [1]. 


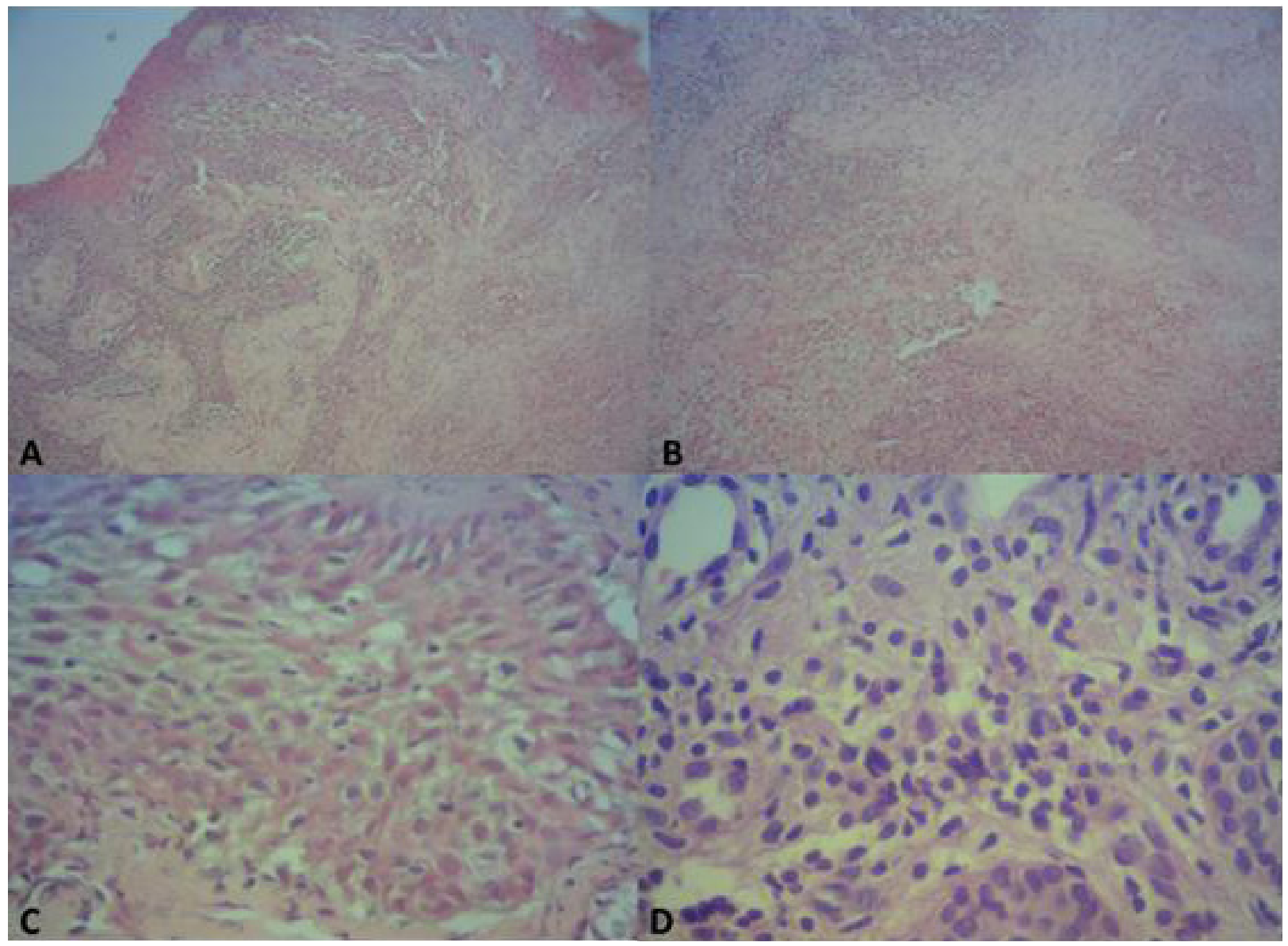

Figure 2. Photo-micrography of primary syphilis. A) Margin of cancer $(\mathrm{HE} \times 100)$. B) Granulomatous formations within the underlying connective tissue $(\mathrm{HE} \times 100)$. C) Spongiosis and exocytosis in the epithelium $(\mathrm{HE} \times 400)$. D) Chronic inflammatory infiltrate with lymphocytes and plasma cells $(\mathrm{HE} \times 1,000)$

Diagnosis of this type of lesion can be complex since oral ulcers are related to a wide spectrum of diseases of different etiologies. In addition, when ulcers result from infections, the presence of non-specific symptoms can make it difficult to identify the disease [10]. In our case, the patient had a painless ulcerated lesion of indefinite evolution time. Due to clinical aspect of the ulcer, it was probably developing for almost 10 days. The absence of pain can contribute to patients neglecting to seek dental care, and the disease normally progresses to secondary phase due to lack of treatment. A biopsy is indicated in cases of ulcer of unknown origin, which do not show signs of healing after 15 days [11]. Diagnosis of syphilis is established through clinical manifestations (signs and symptoms), microscopic examinations, and serological tests [7]. The chancre present in primary syphilis can be diagnosed by dark field microscopy or biopsy. The other stages of the disease are diagnosed by the following serological tests: VDRL and rapid plasma regain. Reactivity to these tests occurs only 1 to 4 weeks after the presence of syphilitic ulceration [7]. Another possible laboratory examination is chemiluminescent microparticle immunoassay. This test is capable of qualitatively detecting antibodies against Treponema pallidum in human serum and plasma. It is indicated as an aid in the diagnosis of syphilis infection. In addition, it can be used as a screening test to prevent transmission of TP to blood, blood components, cells, tissues, and organs [12].

A biopsy, followed by an anatomo-pathological examination was essential in the diagnosis of chancre. In general, biopsy is not routinely used for the diagnosis of syphilis. However, as its findings are suggestive, the diagnosis of syphilis is suspected by a pathologist, and requires serological confirmation. Basic pathology in all stages include edema, proliferation of endothelial cells, and perivascular inflammatory infiltrate with lymphocytes and plasma cells. Blood vessels are dilated, thickened, and endothelial cells proliferate in the primary and secondary stages of syphilis. An inflammatory infiltrate of mononuclear cells and plasma cells of perivascular localization are the most characteristic alterations [13].

Syphilis treatment is based on the stage of the disease, and does not change whether the patient is infected with HIV or not. In primary syphilis, intra-muscular applications of penicillin G (2.4 million units) are used, and are generally 
Table 1. Laboratory data

\begin{tabular}{|c|c|c|}
\hline Laboratory tests & Results & Reference values \\
\hline \multicolumn{3}{|l|}{ Complete blood count } \\
\hline Erythrocytes & $4.71 \mathrm{~m} / \mu \mathrm{l}$ & $4.2-5.9 \mathrm{~m} / \mu \mathrm{l}$ \\
\hline Hemoglobin & $13.0 \mathrm{~g} / \mathrm{dl}$ & $14.0-18.0 \mathrm{~g} / \mathrm{dl}$ \\
\hline Hematocrit & $40.0 \%$ & $42.0-50.0 \%$ \\
\hline Mean corpuscular volume & $84.9 \mathrm{fl}$ & $80.0-98.0 \mathrm{fl}$ \\
\hline Mean corpuscular hemoglobin & $26.8 \mathrm{pg}$ & $28.0-32.0 \mathrm{pg}$ \\
\hline Mean corpuscular hemoglobin concentration & $31.5 \mathrm{~g} / \mathrm{dl}$ & $33-36 \mathrm{~g} / \mathrm{dl}$ \\
\hline Leukocytes & $4.0 \mathrm{k} / \mu \mathrm{l}$ & $0-5 \mathrm{k} / \mu \mathrm{l}$ \\
\hline Basophils & $0.0 \%$ & $0.0-1.0 \%$ \\
\hline Eosinophils & $2.0 \%$ & $0.0-3.0 \%$ \\
\hline Lymphocytes & $34.0 \%$ & $30.0-45 \%$ \\
\hline Monocytes & $6.0 \%$ & $0.0-6.0 \%$ \\
\hline Myelocytes & $0.0 \%$ & - \\
\hline Metamyelocytes & $0.0 \%$ & - \\
\hline Segmented neutrophils & $51.0 \%$ & $50.0-70.0 \%$ \\
\hline Banded neutrophils & $7.0 \%$ & $0.0-5.0 \%$ \\
\hline Neutrophils & $58.0 \%$ & $50.0-70.0 \%$ \\
\hline Reactive lymphocytes & $0.0 \%$ & - \\
\hline Platelets & $42 \mathrm{k} / \mu \mathrm{l}$ & $150-450 \mathrm{k} / \mu \mathrm{l}$ \\
\hline \multicolumn{3}{|l|}{ Other tests } \\
\hline Erythrocyte sedimentation rate & $80 \mathrm{~mm} / \mathrm{hr}$ & $0-15 \mathrm{~mm} / \mathrm{hr}$ \\
\hline Serum glutamic oxaloacetic transaminase & $247 \mathrm{U} / \mathrm{I}$ & $10-40 \mathrm{U} / \mathrm{l}$ \\
\hline Serum glutamic pyruvic transaminase & $171 \mathrm{U} / \mathrm{l}$ & $10-40 \mathrm{U} / \mathrm{l}$ \\
\hline Gamma-glutamyl transferase & $383 \mathrm{U} / \mathrm{l}$ & $9-50 \mathrm{U} / \mathrm{l}$ \\
\hline Glucose & $108 \mathrm{mg} / \mathrm{dl}$ & $70-99 \mathrm{mg} / \mathrm{dl}$ \\
\hline Urea & $31 \mathrm{mg} / \mathrm{dl}$ & $8-20 \mathrm{mg} / \mathrm{dl}$ \\
\hline Creatinine & $0.8 \mathrm{mg} / \mathrm{dl}$ & $0.70-1.30 \mathrm{mg} / \mathrm{dl}$ \\
\hline C-reactive protein & $13 \mathrm{mg} / \mathrm{dl}$ & $\leq 0.8 \mathrm{mg} / \mathrm{dl}$ \\
\hline HIV viral load & 13,442 copies/ml & - \\
\hline CD4+ & 68 cells $/ \mu \mathrm{l}$ & $530-1570 / \mu l$ \\
\hline Calcium & $0 \mathrm{mg} / \mathrm{dl}$ & $8.6-10.2 \mathrm{mg} / \mathrm{dl}$ \\
\hline Potassium & $5 \mathrm{mEq} / \mathrm{l}$ & $3.5-5.0 \mathrm{mEq} / \mathrm{l}$ \\
\hline Sodium & $138 \mathrm{mEq} / \mathrm{l}$ & $136-145 \mathrm{mEq} / \mathrm{l}$ \\
\hline Chemiluminescent microparticle immunoassay & Reactive $($ value $=37.59)$ & Non-reactive \\
\hline
\end{tabular}

*References values from the American Board of Internal Medicine: ABIM laboratory test reference ranges, July 2021.

effective in treating the disease [1]. Moreover, there are other antibiotic alternatives for patients allergic to penicillin [14].

Changes in sexual practices over the years require more attention towards oral sex transmission of sexual diseases [9]. It is known that oral sex can transmit several viral and bacterial diseases, such as syphilis $[15,16]$, but the use of condoms in this sexual practice to prevent the transmission of diseases is still low [17]. For health professionals it is important to be aware of initial manifestations of sexually transmitted diseases in the oral cavity [9]. As syphilis and HIV are sexually transmitted diseases, we may eventually come across patients infected with both the diseases [8]. In addition, syphilis has already been strongly associated with HIV co-infection [18]. It is believed that in the presence of HIV, there may be differences in clinical manifestations of syphilis. HIV-positive patients present more frequently the secondary and latent syphilis since primary manifestations of syphilis are more likely to be asymptomatic [8].

In addition to this scenario, sexually transmitted infections are often asymptomatic in the oral cavity, resulting in 
transmission of infectious diseases through this anatomical region [9]. In the present case report, the patient had a clinical manifestation of primary syphilis on the tongue, and the clinical examination, medical history, and laboratory tests allowed for diagnosing and treating both syphilis and HIV. Follow-up with a serological test is recommended in all patients with syphilis, in order to determine cure after treatment, and to diagnose possible re-infections.

\section{Conclusions}

Sex workers are exposed to a variety of sexual diseases, including HIV and syphilis. In risk groups, health professionals should be alert to genital and extra-genital manifestations of these diseases, especially in the oral cavity, for correct diagnosis and treatment.

\section{Conflict of interest}

The authors declare no conflict of interest.

\section{References}

1. Ficarra G, Carlos R. Syphilis: the renaissance of an old disease with oral implications. Head Neck Pathol 2009; 3: 195-206.

2. Kent ME, Romanelli F. Reexamining syphilis: an update on epidemiology, clinical manifestations, and management. Ann Pharmacother 2008; 42: 226-236.

3. Domantay-Apostol GP, Handog EB, Gabriel MTG. Syphilis: the international challenge of the great imitator. Dermatol Clin 2008; 26 : 191-202.

4. Dourmishev LA, Dourmishev AL. Syphilis: uncommon presentations in adults. Clin Dermatol 2005; 23: 555-564.

5. Kelner N, Rabelo GD, Perez DEC, et al. Analysis of nonspecific oral mucosal and dermal lesions suggestive of syphilis: a report of $6 \mathrm{ca}-$ ses. Oral Surg Oral Med Oral Pathol Oral Radiol 2014; 117: 1-7.

6. Udd SD, Lund B. Oral syphilis: a reemerging infection prompting clinicians alertness. Case Rep Dent 2016; 2016: 6295920.

7. Little JW. Syphilis: an update. Oral Surg Oral Med Oral Pathol Oral Radiol Endod 2005; 100: 3-9.

8. Lynn WA, Lightman S. Syphilis and HIV: a dangerous combination. Lancet Infect Dis 2004; 4: 456-466.

9. Queirós C, Borges da Costa J. Oral transmission of sexually transmissable infections: a narrative review. Acta Med Port 2019; 32 776-781.

10. Sarah GF, Cohen DM, Clark AN. Ulcerated lesions of the oral mucosa: clinical and histologic review. Head Neck Pathol 2019; 13: 91-102

11. Muñoz-Corcuera M, Esparza-Gómez G, González-Moles MA Bascones-Martínez A. Oral ulcers: clinical aspects. A tool for dermatologists. Part II. Chronic ulcers. Clin Exp Dermatol 2009; 34: 456-461.

12. Li Z, Feng Z, Liu P, Yan C. Screening for antibodies against Treponema pallidum with chemiluminescent microparticle immunoassay: analysis of discordant serology results and clinical characterization. Ann Clin Biochem 2016; 53 (Pt 5): 588-592.

13. Avelleira JCR, Bottino G. Sífilis: diagnóstico, tratamento e controle. An Bras Dermatol 2006; 81: 111-126.

14. Arando Lasagabaster M, Otero Guerra L. Syphilis. Enferm Infecc Microboil Clin 2019; 37: 398-404.

15. Edwards S, Game C. Oral sex and the transmission of non-viral STIs. Sex Transm Infect 1998; 74: 95-100.
16. Edwards S, Carne C. Oral sex and the transmission of viral STIs. Sex Transm Infect 1998; 74: 6-10.

17. Mor Z, Gefen D, Linhart Y, Amitai ZS, Dan M, Shohat T. The contribution of oral sex to male urethral Neisseria gonorrhoeae infections in Tel-Aviv district, Israel. Int J STD AIDS 2011; 22: 251-255.

18. Arando M, Fernandez-Naval C, Mota-Foix M, et al. Early syphilis: risk factors and clinical manifestations focusing on HIV-positive patients. BMC Infect Dis 2019; 19: 727. 